\title{
Estado e relações de poder: notas para um debate acerca das politicas públicas
}

\author{
State and power relations: notes for a debate about public policies
}

\section{Hugo Feitosa Gonçalves \\ Rosilene Dias Montenegro}

\begin{abstract}
Resumo
Este ensaio tem como marco teórico o debate sobre "Estado", "relaçôes de poder" e "políticas públicas". Com o objetivo de apresentar um debate teórico-epistemológico e descrever uma base metodológica para análises das relações de poder nas estruturas do Estado capitalista na produção de políticas públicas, busca-se aqui responder: quais categorias são consideradas relevantes, nas diversas perspectivas teóricas, em uma análise sobre processos de produção de políticas públicas? A partir de uma revisão de literatura, este ensaio volta-se inicialmente para apresentar diferentes concepçóes sobre o Estado, políticas públicas e alguns dos mais importantes atores e fatores influentes no processo de produção das políticas. No último momento se apresenta fatores analíticos, a partir de uma perspectiva interacionista, de influência mútua entre as superestruturas e as estruturas sociais, institucionais e individuais, para a análise das relaçóes no processo de produção de políticas públicas.
\end{abstract}

\section{Palavras-chave}

Estado; Políticas Públicas; Relaçôes de Poder; Epistemologia.

\section{Abstract}

This essay has as theoretical framework the debate on "State", "power relations" and "public policies". With the objective of presenting a theoretical-epistemological debate and of describing a methodological basis for analyzing the power relations in the structures of the capitalist State in the production of public policies, we seek to answer: which categories are considered relevant, in the different theoretical perspectives, in an analysis of processes of production of public policies? Based on a review of the literature, this essay turns initially to present different conceptions about the State, public policies and some of the most important actors and influential factors in the process of policy making. At the last moment we present analytical factors, from an interactionist perspective, of mutual influence, between the superstructures and the social, institutional and individual structures, for the analysis of the relations in the process of production of public policies.

\section{Keywords}

State; Public Policy; Power Relations; Epistemology. 


\section{6 | Hugo Feitosa Gonçalves e Rosilene Dias Montenegro}

\section{Introdução}

O presente trabalho parte do questionamento sobre quais atores e fatores são os principais determinantes no processo de produção das políticas públicas de acordo com as diversas, e por vezes divergentes, perspectivas teóricas. A partir de uma breve revisão de literatura, tem-se como objetivo apresentar, mesmo que introdutoriamente, um debate teórico-epistemológico sobre uma parte significativa dos fatores determinantes no processo de produção das políticas públicas no tipo de Estado capitalista.

Este trabalho pretende contribuir com a discussão sobre as visões, categorias e concepções sobre Estado e políticas públicas a partir de algumas das mais difundidas perspectivas sobre o tema, como: a de Estado parasita e expropriador do bem-estar social, dos liberais; de Estado arena, dos pluralistas; de Estado autônomo dos interesses externos, dos institucionalistas; de Estado como instrumento de dominação, dos marxistas; e de Estado como relação de sobreposiçôes de poder, dos neomarxistas; reconhecendo as particularidades estruturais (institucionais e de relações) em cada região e ressaltando que as publicações revisadas para esta discussão, em geral, fazem uma abordagem generalizante sobre esse tipo de instituição-estrutura, especificamente, inserida ou regida em um modo de produção $^{1}$ predominantemente capitalista.

A percepção sobre o Estado e o poder de influência de suas estruturas e seus controladores oficiais, governantes e burocratas, e fraçóes sociais específicas sobre as políticas públicas varia de acordo com as correntes de pensamento sobre o Estado. Mesmo sendo de correntes teóricas diferentes, derivadas de perspectivas epistemológicas e ideológicas diferentes, autores marxistas, como os próprios Karl Marx e Friedrich Engels (de uma forma mais extrema), Nicos Poulantzas (com uma concepção mais relativista), cientistas políticos contemporâneos, como Michael Howlett, assim como cientistas econômicos nacionais, como Bresser-Pereira, consideram que as fraçóes detentoras do poder econômico exercem uma influência diferenciada nas ações dos Estados capitalistas. Com base em um recorte bibliográfico de uma tese, em conclusão, sobre as políticas públicas do Estado brasileiro no período de hegemonia neoliberal, em função de compactar o referencial teórico e o debate aqui proposto, a revisão da literatura sobre as diversas concepções de Estado, políticas

\footnotetext{
${ }^{1} \mathrm{O}$ termo "modo de produção" aplica-se aqui de acordo com a concepção marxista de produção, além da material-econômico, ideológica e política.
} 
públicas e influenciadores das açóes do Estado, volta-se ao debate entre esses e outros autores.

A partir do debate entre as concepções sobre o Estado (em foco, as relações sociais nas quais o Estado está inserido) e políticas públicas (em questão, o processo de produção/formação das políticas), introduz-se aqui uma discussão sobre uma parte significativa das categorias relevantes para a discussão sobre os determinantes das açôes do Estado, dentre essas categorias: i) os atores; ii) os regimes políticos; iii) as estruturas; iv) as conjunturas; v) o poder; vi) o discurso; vii) a ideologia; e viii) o direito.

\section{Atores e fatores relevantes no processo de produção da politica pública}

Propõe-se nas próximas seções introduzir alguns dos conceitos, concepções e categorias relevantes para uma análise sobre Estado, políticas públicas e potenciais fatores e atores influenciadores no processo de produção das políticas públicas, para em seguida finalizar este ensaio apresentando orientaçôes epistemológicas para a análise. As concepçóes, categorias e conceitos são apresentados aqui como bases para a formulação do método, não como pressupostos.

Muitos dos autores aqui referidos partiram de análises de construções epistemológicas e/ou conjunturas diferentes. Portanto, esta revisão de literatura não se volta para as negações, mas para as possíveis contribuições que esses autores podem trazer para a análise.

\section{Sobre o Estado}

O debate sobre o Estado, especificamente capitalista, volta-se para os ensaios de Marx (e Engels), do (neo)marxista Poulantzas; do cientista político estadunidense Howlett; e do neodesenvolvimentista da teoria econômica brasileira, Bresser-Pereira, todos apresentados a partir de uma ordem cronológica e territorial - da Europa Central (historicamente dominante na produção do conhecimento) para o Brasil.

Marx e Engels escrevem no período entre a emergência e propagação acelerada da indústria (meados do século XIX); no foco desses acontecimentos, a Europa Central, onde se podia observar claramente quem eram os donos dos meios de produção (os industriais), quem servia sua força de trabalho aos meios de produção (os trabalhadores da indústria) e o (re)conhecimento de pertencimento de classe social dos indivíduos em geral (o local que esses ocupavam no processo de reprodução material, a classe "em si"), inclusive dos que ocupavam os cargos de direção 


\section{8 | Hugo Feitosa Gonçalves e Rosilene Dias Montenegro}

dos Estados. Para esses autores, as formas de Estado não podem ser compreendidas por si mesmas, nem como um fator evolutivo natural, mas como instituição inserida nas condiçôes materiais de existência da sociedade - um órgáo originado pela sociedade com o propósito de suprir as demandas comuns e defender seus limites espaciais a ataques físicos promovidos de dentro e de fora das suas fronteiras. Entretanto, uma vez criado, o Estado "[...] se torna independente da sociedade" (MARX e ENGELS, 2010, p. 133) e, ao longo do tempo, se converte em um órgão de determinada classe, legitimando o domínio dessa classe (MARX, 1977).

Poulantzas escreve na segunda parte do século XX, especificamente entre os anos de 1966 a 1978, também na Europa Central, com o capitalismo (como sistema de produção material, social e ideológico) já consolidado enquanto sistema hegemônico mundial - apesar de no período existir um significativo bloco de Estados não capitalistas de mercado, comandado pela União Soviética -, depois de ter passado por diversas crises "conjunturais" e "orgânicas" - tomando a expressão de Antônio Gramsci - e por diversas reformulações materiais e ideológicas. Para Poulantzas (1977 e 1980), o Estado capitalista não se expressa como uma ditadura da classe, moldado apenas para satisfazer os interesses dos dominantes, mas é um refletor e materializador das lutas de classes. Esse tipo de Estado tem uma autonomia relativa como negociador e apaziguador das relaçóes de classes para manter a coesão social, mas atuando em função da manutenção do poder político das classes dominantes.

Howlett, Ramesh e Perl (2013) fazem um levantamento sobre diversas correntes do pensamento político e suas concepçôes sobre Estado e políticas púbicas, das quais destacam: a public choice dos (neo)liberais, que consideram o Estado como uma espécie de parasita do produto social e, assim, expropriador do bem-estar social, que não deveria interferir nas relações econômicas, pois o mercado livre regularia essas relaçôes, aumentando o bem-estar social. Assim, o Estado deveria atuar apenas nos setores que não fossem de interesse do capital; o (neo)pluralismo, que observa o Estado como uma arena onde os grupos de interesses, reconhecidos pelo Estado, se relacionam em função de atender suas demandas; e o (neo)institucionalismo, que defende que existe uma autonomia do Estado em relação aos interesses das frações sociais, em que, além dos grupos da esfera civil, atores estatais com seus interesses específicos, também participam das relações no processo de produção das políticas públicas, sobrepostos pelos interesses institucionais etc.

A ciência política de Howlett, Ramesh e Perl (2013) considera que as açóes do Estado são movidas pelas estruturas institucionais e sociais (por interesses coletivos e individuais) em questão: i) a estrutura do regime de produção e suas ideologias 
políticas dominantes, o "capitalismo democrático-liberal"; ii) os interesses de grupos que possuem poder econômico e/ou organizativo; iii) e os interesses específicos de governantes e burocratas do Estado. Os interesses do "público" (os eleitores) e dos partidos políticos teriam um papel secundário, enquanto os meios de comunicação possuem uma influência indireta, mas significativa.

O teórico neodesenvolvimentista brasileiro Bresser-Pereira (2010) - baseado na concepção de Poulantzas (1980) - diferencia sua concepção do teórico marxista na proporção de poder entre a autonomia do Estado (Bresser se volta apenas à institucionalidade desse tipo de Estado) e as pressóes dos que detêm o poder econômico. Bresser-Pereira (2010), mais aliado à concepção institucionalista, considera que o poder econômico exerce uma pressão relativa sobre o Estado, especificamente sobre a prática política, mas essa instituição e seus atores, em questão os burocratas, possuem uma autonomia maior do que as pressões que qualquer fração social impõe.

A partir dessas diferentes, por vezes divergentes, concepçôes sobre o Estado, percebe-se o Estado como uma arena-ator de sobreposiçóes de poderes (materiais e ideológicos) de frações sociais e individuais, inserido e (re)estruturado em um determinado, e relativamente determinante, modo de produção.

\section{Sobre politicas públicas}

Para o filósofo e militante comunista francês do século XX Daniel Bensaïd (1999, p. 131), “[...] a política passa à frente da história”. A política (materializada no Estado) é um fator de formação e transformação das estruturas sociais.

Para a perspectiva marxista no geral, as açôes do Estado são produtos-reflexos das relações de imposição, ou sobreposição, de poder de classes e frações de classe.

A partir de uma perspectiva descritiva, o cientista político brasileiro contemporâneo Leonardo Secchi (2016), tecnicamente, a partir de uma perspectiva neopluralista, compreende as políticas públicas como diretrizes elaboradas para enfrentar um problema considerado público pelos "atores estatais". Além desses atores, as políticas públicas podem ser influenciadas por "organizações não governamentais", dentro de um conjunto de regras aceitas pelo Estado.

Para Howlett, Ramesh e Perl (2013), as políticas públicas são tentativas de resoluçóes de problemas de determinados atores por meios públicos, uma resposta dos "atores políticos" (estatais) a pressões de frações sociais, ideologias e interesses próprios, considerando fatores estruturais e conjunturais. Para os autores, as políticas 
públicas são cada vez mais voltadas para "grupos de interesse especial", em detrimento dos interesses dos eleitores.

Com a pretensão de facilitar o estudo sobre políticas públicas, Howlett, Ramesh e Perl (2013) retomam a perspectiva de "ciclo da política pública", que divide analiticamente por estágios temporais o processo que vai da "montagem da agenda" (da legitimação e formalização de um problema pelos atores políticos) até a implementação e avaliação, ou arquivamento, da política. Os autores ressaltam que, na prática, a sequência dos estágios não necessariamente segue uma ordem determinada previamente por essa perspectiva, nem são cumpridos todos os estágios (HOWLETT, RAMESH e PERL, 2013).

Propõe-se aqui considerar o processo de formação da política pública como uma construção a partir de relações de sobreposiçóes de poderes estruturais, de frações sociais e também individuais, inserida em uma determinada conjuntura de uma estrutura econômica, social, política e institucional, em função de interesses específicos, ao menos que não abarcando os interesses de toda a população, como homogênea e unidade de interesses, fracionada por interesses diferentes e/ou divergentes relacionados, ou não, com "visões de mundo" dos atores - tomando o termo usado por Michel Löwy (1989).

\section{Sobre atores, regimes, estruturas e conjunturas}

Esta seção apresenta os potenciais influenciadores das políticas públicas. Howlett, Ramesh e Perl (2013) consideram como atores das políticas: i) os atores políticos (legisladores, executivos e burocratas do Estado), em primeiro plano, e partidos políticos e eleitores em segundo plano; ii) os "grupos de interesse", ou "organizações coletivas", principalmente as organizaçóes de empresários, nacionais e internacionais - representações de frações da classe capitalista para Poulantzas (1977) -, como exemplo, o Banco Mundial (BM) e o Fundo Monetário Internacional (FMI), e os sindicatos dos trabalhadores, como a Central Única dos Trabalhadores (CUT); e iii) os meios de comunicação.

Outro fator que Howlett, Ramesh e Perl (2013) destacam como influente nas ações públicas são os regimes político-econômicos adotados pelos Estados, em questão, o regime "capitalista-democrático-liberal" e suas ideologias dominantes, em uma estrutura de Estado federalista-presidencialista, tipo que se assemelha à estrutura político-institucional do Estado brasileiro de hoje. Esse regime capitalistademocrático-liberal se aproxima do que a teoria marxista considera uma 
"superestrutura", promulgadora das "leis gerais", que moldam e são moldadas pela "infraestrutura" (econômica e ideológica) social.

Por fim, Howlett, Ramesh e Perl (2013) consideram também as conjunturas - em destaque, as situaçóes macroeconômicas e sociais como influentes nas ações do Estado. Para os autores - em concordância com David Harvey (2011) e com a ensaísta Viviane Forrester (1997) -, no regime capitalista, em um período de crise econômica, por exemplo, as políticas voltam-se mais para atender os interesses do capital, em detrimento dos interesses dos trabalhadores, que se desarticulam na busca de permanecerem empregados ou por estarem desempregados.

Além da situação política, macroeconômica e social, em um Estado tipo capitalista-democrático, onde o sufrágio universal é fator relevante, propõe-se voltar às análises do comportamento dos atores considerando as especificidades das formaçôes socioeconômicas e fatores conjunturais das formaçôes/produções das políticas públicas, inclusive para as situações e períodos eleitorais.

\section{Sobre classes e frações de classe}

A teoria marxista percebe as classes e frações de classes como atores centrais, e as suas relaçôes, em questão, as "lutas políticas", configuram a superestrutura, regente das estruturas econômicas, sociais e institucionais, como o Estado e as instituiçóes gerenciadas por ele. Para Marx (2008) e Engels (1951), são os indivíduos que fazem a história, mas a partir de condições previamente estruturadas.

As classes sociais no mundo moderno - derivado da revolução industrial em meados do século XVIII - dividem-se amplamente, mas não exclusivamente, entre os que possuem os meios de produção (o "capital") e exploram a força de trabalho (os "burgueses"), e os que possuem apenas sua força de trabalho e a vendem como mercadoria, subordinada à dinâmica econômica, para poder sobreviver (o "proletariado") (MARX e ENGELS, 2012).

Hoje essa estruturação de alocação categórica de pertencimento de classe a partir da posse dos meios de produção, está passando por profundas transformaçóes, o que gera dificuldades para se conseguir enxergar de imediato a "classe em si"2; como é o caso do desenvolvimento da extração da mais valia absoluta e relativa, realizada a partir da terceirização de serviços, explorando a força de trabalho e os instrumentos

${ }^{2}$ Termo usado pelo marxismo para enquadrar o pertencimento de classe dos agentes sociais a partir do local que esses ocupam no processo de produção econômica, mas não necessariamente nas relaçóes (lutas) políticas. 
do trabalhador, sem o capital ter compromisso nenhum com a reprodução da força de trabalho, nem dos instrumentos de trabalho, como é o caso a "uberização". Além de as classes não necessariamente formarem uma unidade de interesse e representação, principalmente a classe trabalhadora, que vezes se dispersa por motivos ideológicos ou por questão de sobrevivência.

De acordo com Poulantzas (1977), as classes sociais "em si” são condicionadas a partir da sua posição na divisão social do trabalho e são independentes da vontade dos indivíduos; no entanto, as classes sociais são determinadas, além do nível econômico, também pelos níveis político e ideológico. Poulantzas apud Rojas e Amadeo (2017) define uma classe social como um conjunto de agentes sociais determinados principalmente, mas não exclusivamente, pelo seu lugar no processo de produção na esfera econômica. Para o autor em questão, na prática, o local das relações de produção econômica é determinante, mas existe uma contribuição da superestrutura política e ideológica para a reprodução das relaçôes de produção materiais e sociais - principalmente hoje, que a produção é cada vez menos realizada em grandes fábricas, e os trabalhadores não se relacionam mais rotineiramente para se reconhecerem como classe.

Para Marx e Engels (2010) a burguesia não é uma classe homogênea, e suas frações se encontram também em luta (material e ideológica) permanente. Para Poulantzas (1977), a classe burguesa fraciona-se, em nível econômico, entre outros, em comerciantes, industriais e financistas. Ao nível político, existe uma divisão mais complexa de acordo com as formações econômicas e sociais específicas de cada país.

Mutti e Segatti apud Rojas (2015) conceituam as frações da burguesia latinoamericana como: i) "burguesia compradora", vinculada aos interesses imperialistas ${ }^{3}$; ii) "burguesia nacional”, formada por agentes locais, com uma relativa autonomia em relação ao capital externo, estruturada a partir da formação econômica proporcionada por fatores endógenos, com posição geralmente anti-imperialista e/ou populista; iii) "burguesia interna", estruturada por agentes locais que convivem passivamente com a burguesia compradora, pois não têm autonomia em relação ao capital internacional; e, iv) "burguesia de Estado", que emerge no campo político para o econômico.

Em relação à "pequena burguesia", Rojas e Amadeo (2017) apresentam um debate conceitual entre Poulantzas e Eric Olin Wright. Enfatiza-se aqui uma questão destacada por Poulantzas (apud ROJAS e AMADEO, 2017), que essa fração social

\footnotetext{
${ }^{3}$ Sobre o "imperialismo capitalista", ou o "novo imperialismo", ver: "O Imperialismo: fase superior do capitalismo” (LENIN, 1987) e “O Novo Imperialismo” (HARVEY, 2010).
} 
busca a ascensão econômica e social individualmente, aparentemente não estruturando organizaçóes coletivas representativas autônomas, posto que se relaciona com possíveis dificuldades da chamada "pequena burguesia" em estruturar representações coletivas significativas para influenciar as ações do Estado brasileiro.

Para Marx (2008) e Poulantzas (1977), existe uma unidade de diferentes interesses das fraçóes da burguesia que têm em posse o poder do Estado, comandada periodicamente por uma dessas frações - o que é conceituado por Poulantzas (1977) como "bloco no poder", ou seja, os maiores influenciadores das ações do Estado.

\section{Sobre o poder}

Para Marx apud Poulantzas (1980), o poder, no modo de produção capitalista, se estabelece e se reproduz no processo de produção, constituindo relações de dominação econômica, ideológica e social que são importadas para as estruturas e relaçôes do/no Estado.

Bianchi (2007) destaca a concepção de Miliband, que afirma que existe uma profunda relação entre o "poder econômico" e o "poder político", assim, a classe que possui os meios de produção, em razão do seu poder econômico, tem o Estado como instrumento de dominação social.

Para Foucault (2007), o poder não se reduz à dominação de uma classe social sobre a outra e não se concentra apenas nas estruturas do Estado, mas se expressa em múltiplos (re)produtores de dominação social.

Ao defender a concepção marxista, questionando a concepção de Foucault, Boito Junior (2007, p. 33) defende que é o poder de comandar os rumos da economia, de decidir se o país entra em guerra ou não, (de alterar os direitos dos trabalhadores), que influi naquilo "que mais afeta a posição dos indivíduos na sociedade e suas condições de vida”.

A diferença no grau de relevância da instituição Estado e das classes sociais como campo de reprodução de poder e controle social, em função de fatores produtivos-econômicos, não interfere na leitura de que ambas as concepçóes apresentam o Estado como estrutura de materializaçáo e reprodução do poder social dominante.

\section{Sobre o discurso}

Sobre o discurso, o debate parte do foco analítico individual e da perspectiva de indivíduo autônomo em Foucault (2012), passando pela perspectiva de discurso social estruturado por fraçóes sociais em Marx (2008). Em seguida volta-se para o 
debate da influência das estruturas e conjunturas na construção do discurso e o uso desse como instrumento de fraçôes sociais em Thompson (1995). Depois, apresentase a ideia dialética de inter-relação entre estruturas sociais e a autonomia do sujeito na produção do discurso em Pechêux (apud CESÁRIO e ALMEIDA, 2010). Encerra-se esta seção apresentando as orientações sobre atenção nos discursos políticos possivelmente disfarçados de supostos interesses coletivos, encobrindo interesses que podem ir além dos registrados oficialmente pelos atores estatais, conforme apresentado por Howlett, Ramesh e Perl (2013), e demais atores, como defende Boito Junior (2016).

Em “A Ordem do Discurso", Foucault (2012, p. 8-9), considerando a autonomia do indivíduo perante as estruturas sociais, defende que a produção do discurso dos indivíduos é controlada, selecionada, organizada e reformulada constantemente para "[...] conjurar seus poderes e perigos", para ser tomado como uma "verdade" aceita por determinados espectadores.

Analisando o discurso na prática das leis estabelecidas pelas classes sociais dominantes e do Imperador francês de meados do século XIX, Luís Bonaparte, Marx (2008) mostra que as leis institucionais do Estado escondem a opressão autolegitimada pelo Estado sob o argumento de "segurança nacional", enquanto Bonaparte assume um discurso de representante de frações sociais antagônicas em função de ocultar os diferentes e divergentes interesses de classes, fraçôes de classe e pessoais, e o uso do Estado como instrumento de poder econômico para manter a exploração social.

Voltando a atenção para o discurso de massa, Thompson (1995) apresenta o discurso como instrumento de propagação ideológica em função da dominação social, produzido com inserçóes de fatores simbólicos, encobrindo outros, mas não necessariamente em função de iludir, inter-relacionado com fatores estruturais (sociais e institucionais) e conjunturais (sociais, econômicos, políticos) e muitas vezes não explícito.

Para Pêcheux (apud CESÁRIO e ALMEIDA, 2010), interessado pelos sujeitos coletivos, o discurso é estruturado com a influência: i) da estrutura da consciência (o eu) - perspectiva foucaultiana - ("formaçôes discursivas"); ii) da ideologia (inconsciente), esta estruturada pela conjuntura das estruturas das relaçóes de classes (estruturas capitalistas), estruturas religiosas, estruturas morais, etc., influenciando "o que pode ser dito", que influencia as formaçôes discursivas; iii) do processo de produção histórica do discurso, que influencia e é influenciado pelas formaçóes ideológicas. Para o autor marxista althusseriano, existe uma autonomia 
relativa do sujeito - o autor não usa essa expressão - das estruturas sociais e de sua posição social na formulação do discurso, possibilitando a ocorrência de uma desestruturação das redes de memórias e dos trajetos sociais nos quais ele irrompe (PÊCHEUX apud CESÁRIO e ALMEIDA, 2010). Em síntese, o discurso seria uma relação entre estruturas sociais e autonomia do sujeito. Pêcheux (apud CESÁRIO e ALMEIDA, 2010) apresenta-o como não necessariamente falso, mas uma representação influenciada pelas suas condições reais de existência; e propõe considerar as conjunturas e estruturas sociais nas quais o sujeito está inserido, e o que está explícito, implícito, a falta, a falha e o silêncio do/no discurso.

Voltando-se para os discursos dos atores políticos, Howlett, Ramesh e Perl (2013) afirmam que esses atores podem anunciar razões de uma decisão que não são as razões reais pelas quais a decisão foi tomada, defendendo que os interesses em relação às tomadas de decisões do poder público vão além dos registrados oficialmente. De forma semelhante, Boito Junior (2016) considera que os demais atores também escondem interesses específicos para defender determinadas açóes do Estado.

\section{Sobre ideologia}

Inicialmente, discorre-se brevemente nesta seção sobre o processo histórico da formação da concepção sobre o termo "ideologia" a partir de um debate de alguns autores marxistas, finalizando com a apresentação de alguns dos mais influentes autores e suas ideologias em torno do Estado a partir de um percurso histórico.

O marxista franco-brasileiro Michel Löwy (1989) apresenta as construções e reformulações da concepção sobre "ideologia", assim como demais categorias, como um processo histórico, de reorientações do termo para expor determinadas questôes em determinados períodos. Voltando-se para a concepção marxista de ideologia, o autor apresenta que Marx, após reorientaçóes sobre o termo, mostra a ideologia como formas "[...] através das quais o indivíduo e a sociedade tomam consciência da via real” e que são vinculadas com uma posição de classe. Para Lênin (apud LÖWY, 1989), a ideologia é uma concepção da realidade social ou política propagada em função de interesses de classes. Para o próprio Löwy (1989), a ideologia é um conjunto estruturado de valores, representaçóes, ideias e orientaçóes cognitivas, como "visôes do mundo", derivadas da dialética classista. De acordo com Boito Junior (2016), a ideologia é uma categoria influente nas ações dos indivíduos, mas não é determinante. 
De acordo com Poulantzas (1980), uma ideologia não se limita a um sistema de ideias ou de representaçóes; compreende também uma série de práticas materiais extensivas aos hábitos, aos costumes, ao modo de vida dos indivíduos, agindo no conjunto das práticas sociais - entre essas, as práticas econômicas e políticas. Para o teórico marxista, a ideologia não é algo neutro na sociedade, só existe em função de uma determinada classe ou fração de classe. A ideologia dominante consiste em um poder essencial da classe dominante. Essa ideologia dominante invade os aparelhos do Estado, e demais estruturas e relações sociais, os quais são funcionais na elaboração, reprodução e propagação ideológica e de poder.

Assim como a concepção de autonomia relativa do Estado em relação às classes dominantes, a percepção de Poulantzas (1977) sobre a ideologia dominante torna-se um marco importante da teoria crítica marxista. Para Poulantzas (1977), a ideologia dominante não expressa apenas os interesses e concepçóes de modo de vida das classes dominantes. Essas não seriam as únicas classes-sujeito da história. A ideologia dominante reflete "relações políticas 'concretas' em uma formação social entre as classes dominantes e classes dominadas". Ela compóe "[...] elementos decorrentes do modo de vida de outras classes ou frações que não a classe ou fração dominantes [...]" (POULANTZAS, 1977, p. 197).

$\mathrm{O}$ autor considera que essa relação de absorção de componentes de "modos de vida” de outras classes, ou fraçóes de classe, corresponde tanto à ideologia da classe ou fração de classe dominada, que pode ser composta por componentes ideológicos das classes dominantes, quanto a componentes ideológicos das classes dominadas, que podem ser absorvidos pela ideologia (da classe) dominante. Poulantzas (1977) defende a possibilidade de uma série de defasagens entre a ideologia dominante e os interesses das classes, ou frações de classe, politicamente dominantes.

As ideologias em torno do funcionamento do Estado também se apresentam como construções históricas voltadas a atender determinados interesses a partir de períodos conjunturais em determinadas estruturas socioeconômicas, em determinados territórios, como - apesar de não terem usado os termos que historicamente foram classificados e categorizados por outros autores - o "liberalismo", derivado das concepções de Adam Smith, David Ricardo, Robert Malthus, etc., no século XVIII, e seus seguidores posteriormente; o "reformismo", que emerge no século XIX com John Stuart Mill, dentre outros; o "socialismo" de Marx e Engels, entre outros, emergido no século XIX; o "desenvolvimentismo" de John Maynard Keynes, em meados do século XX, influenciador da corrente desenvolvimentista na América Latina; o "neoliberalismo" de Friedrich August von Hayek, Paul Anthony Samuelson 
e, para a/na América Latina, dos chamados "Chicago Boys", liderados por Milton Friedman, na segunda parte do século XX, etc. (HUNT, 1989; PEREIRA, 2011; SISCÚ, PAUA e MICHEL, 2007).

Essas ideologias em torno do Estado apresentam-se umas como utopias, de acordo com a definição do termo de Karl Mannheim (apud LÖWY, 1989), e outras como defesa das açóes previamente praticadas pelos/nos Estados.

\section{$O$ direito para o marxismo}

A partir de textos de Marx, Bensaïd (1999, p. 197) apresenta uma concepção "não jurídica de justiça" e considera, em crítica apresentada como "teoria da justiça", que existe uma falsa equitatividade que rege as relaçóes individuais na sociedade. $\mathrm{O}$ direito capitalista iguala os indivíduos que ocupam posiçóes socioeconômicas desiguais, tornando o Estado aparentemente universalista. Nenhum direito seria inteiramente autônomo nem estaria acima dos regimes econômicos e sociais, seus valores e ideias (BENSAÏD, 1999; POULANTZAS, 1977).

O regime capitalista, ao tratar o trabalho como uma mercadoria, apresenta uma espécie de "igualdade abstrata". Todos os indivíduos seriam tratados igualmente como trocadores (MARX apud HUNT, 1989). A igualdade formal produz um efeito de individualização dos agentes sociais em função da pacificação dos conflitos de classes e eliminação dos efeitos ideológicos não individualistas, além de propagar uma ideia de unidade social, de povo-nação, escondendo a diferenciação de poder e de interesses entre as diversas frações sociais (BENSAÏD, 1999).

A perspectiva marxista considera que as estruturas institucionais, os interesses e relaçôes individuais são relevantes perante as ações do Estado, mas defende que as estruturas (entre elas, as instituições do Estado capitalista) foram construídas historicamente em função de interesses específicos de frações sociais, não restritas territorialmente, dominantes do sistema político-econômico regente. Essas estruturas (políticas-institucionais) proporcionam relaçôes coletivas e individuais, e essas relações, previamente estruturadas, são reforçadas ou desestruturadas pela dinâmica dos atores. Marx (2008 [1852]) e Engels (1951 [1890]) afirmam que são os indivíduos que fazem a história, mas a partir de condiçóes previamente determinadas.

\section{Notas Epistemológicas}

A partir desse debate introdutório sobre Estado, políticas públicas e fatores determinantes no processo de formação dessas, as notas epistemológicas apresentadas aqui para as pesquisas que objetivam analisar as relaçóes de poder no processo de 
produção de políticas públicas, derivam também de uma revisão de literatura sobre ontologia e epistemologia contemporânea nas ciências sociais e políticas, considerando as orientaçóes: i) da crítica da busca pela legitimação da teoria na pesquisa, sem considerar as especificidades dos fenômenos, por Gusmão (2012); ii) da crítica à redução do conhecimento a fatores teóricos e totalizantes, do realismo crítico de Bhaskar e Archer (apud HAMLIN, 2017); iii) para a observação das relações individuais, das estruturas, etc., do construcionismo crítico; iv) para a análise, além das estruturas sociais, das performances dos atores - não só das ações explícitas/explicitadas, mas também fatores hermenêuticos -, do "programa forte" de Alexander (apud BRASIL JUNIOR e OLIVEIRA, 2014) e do estudo político proposto por Howlett, Ramesh e Perl (2013); v) para considerar os interesses individuais, mas dentro de uma estrutura social, que é a sociedade capitalista, como defendido por Bensaïd (1999) e Meszaros (2009), em concordância com Marx (2008) e Engels (1951); vi) para o reconhecimento de Meszaros (2009) e Löwy (1989) de que as próprias perspectivas e categorias são instrumentos passíveis de interesses de frações sociais; e vii) de Althusser (1975) sobre o risco de recair apenas na superfície das relações sociais da análise empírica sem uma interpretação teórica.

Não se ousa pretender abarcar todos os fatores atuantes sobre os objetos. A ênfase analítica proposta é uma idealização - de acordo com termo weberiano - dos elementos constituintes dos objetos, baseada na revisão de literatura sobre os atores e fatores relevantes no processo de produção de políticas públicas.

Os atores enfatizados pela literatura aqui revisada são: as estruturas institucionais (suas normas e regras, oficiais ou não), as fraçôes sociais, como as classes sociais, frações de classe ou grupos de interesses e suas representações coletivas (nacionais e internacionais), os meios de comunicação, os atores estatais e seus interesses específicos, em primeiro plano; e os eleitores, os partidos políticos e seus interesses, que, apesar de poderem ser considerados, aparentemente são atores secundários na produção de políticas públicas, ao menos em relação às políticas macroestruturantes, no Estado capitalista.

Entre os fatores em destaque, inclui-se as estruturas sociais, os regimes político-econômicos regentes, as especificidades conjunturais, as ideologias dominantes, as ações materiais e os discursos dos atores. Em relação à análise dos discursos, propóe-se considerar não apenas as questóes explícitas contidas neles, mas também fatores estruturais, conjunturais, ideológicos, de posições de poder (econômico, social, institucional) e interesses particulares implícitos em tais discursos, a fim de produzir uma análise hermenêutica. 
Orienta-se, a partir da literatura aqui introduzida, que a análise das ações específicas dos atores, considerando as particularidades conjunturais inseridas e derivadas em/de um determinado regime político-econômico, de uma determinada estrutura econômica-social, é relevante para conseguir verificar os interesses e as relaçóes de (sobreposiçóes de) poder de frações sociais, e também individuais, distintos no processo de produção de políticas públicas.

Considera-se aqui que a concepção (neo)liberal parte de pressupostos ideológicos-discursivos não empíricos, dentre esses: que todos os indivíduos têm como objetivo acumular bens de consumo, negando o modo de vida de índios, quilombolas, grupos identitários, etc.; que todos os indivíduos (que pretendem acumular) têm o mesmo acesso à produção, desconsiderando as relações históricas de apropriação primitiva, as quais tiveram contribuição do Estado e pelas quais grupos foram tirados dos territórios que habitavam, se não pelo convencimento, pela força, e que pessoas foram/são escravizadas e negadas historicamente a direitos de pertencentes à sociedade; ao defender o afastamento do Estado das relaçóes econômicas diretas, o livre mercado desconsidera que territórios colonizados e seus produtos foram estruturados para atender interesses de países centrais e não aos interesses da sua população, ficando à margem do processo de desenvolvimento da produção, assim produzido com baixo valor agregado; e também não considera a relação direta de sobreposição de interesses do capital, principalmente o capital especulativo financeiro, nas (rel)açóes do Estado, o que faz essa perspectiva se voltar aos custos sociais do Estado, ou custos de reprodução da força de trabalho, que inclusive o desagrega dos custo de produção, como usurpador do produto e, assim, das forças produtivas do mercado (HARVEY, 2011; FERNANDES, 1988).

A concepção (neo)pluralista de Estado arena-árbitro das relações de interesses também desconsidera a sobreposiçáo dos detentores do poder econômico sobre os demais atores, e da aliança que envolve financiamento, respostas aos seus interesses e interesses materiais-ideológicos conjuntos entre os detentores do poder econômico e atores estatais. Enquanto os (neo)institucionalistas, apesar de considerarem os interesses sociais e individuais também dos atores estatais no processo de produção das políticas públicas, defendem que o Estado tem uma autonomia em relação aos interesses dos "grupos de pressão" e age em função da sua reprodução, e como Estado que se estrutura e se reproduz no modo de produção capitalista, age em função da reprodução do capital por interesses internos, pressuposto esse que é desmontado na obra de James O'Connor (1977), que analisa o Estado americano, ao mostrar como 
pode ser percebido também no Brasil que o Estado se volta aos interesses do capital mesmo sem contrapartida de produção de valor, e assim de recursos para o Estado, abstraindo recursos em proporções maiores da classe trabalhadora em relação à classe capitalista. Como fatores empíricos, se observa a carga tributária regressiva e o "sistema da dívida pública" (ARAÚJO, 2000; FATTORELLI, 2015).

Aqui também se faz uma ressalva à leitura que fazem do marxismo ortodoxo, de Estado como apenas instrumento da classe dominante, ao perceber alguns momentos pontuais de conquistas, não sem muita luta das frações não dominantes, ou não hegemônicas, e também não sem haver outra alternativa para o capital, como ocorreu nos governos do Partido dos Trabalhadores (PT) no Brasil, quando houve um aumento real da renda e de acesso a moradia, educação etc. entre os mais pobres, mas sem romper com os interesses, com o lucro, do capital financeiro, condicionado por um período de dinâmica econômica mundial ${ }^{4}$.

Considera-se aqui a concepção neomarxista de Poulantzas (1977, 1980 e 2008), ao avaliar que o Estado não é um sujeito autônomo nem um instrumento de dominação, mas que, como uma percepção dialética desse debate, o Estado capitalista é uma relação de interesses e sobreposições de poder que não se separa das relações da esfera civil, mas que tem uma autonomia relativa dos interesses de curto prazo da classe capitalista, fazendo concessóes à classe trabalhadora quando necessário para evitar revoltas e manter a reprodução do modo de produção capitalista. Em relação a quão autônomo seria o Estado, Poulantzas (2008) afirma que depende da formação socioeconômica e da conjuntura na qual ele está inserido.

Então, percebe-se os interesses particulares, as ideologias e os discursos dos atores estatais, midiáticos, institucionais, como o direito etc., como inseridos e condicionados por essas relações, de sobreposições de poder e interesses, dialéticas estruturais e conjunturais.

\footnotetext{
${ }^{4}$ Sobre a evolução dos dados sociais nos governos do PT ver: Gonçalves e Montenegro (2017), em "Desenvolvimento do Nordeste nos Governos FHC e Lula".
} 
- Hugo Feitosa Gonçalves é Doutorando do Programa de PósGraduação em Ciências Sociais - PPGCS, da Universidade Federal do Rio Grande do Norte (UFRN). E-mail: hugofg@live.com.

- Rosilene Dias Montenegro é Doutora em História pela Universidade Estadual de Campinas. Professora da graduação e da Pós-Graduação em História - PPGH, da Universidade Federal de Campina Grande (UFCG), e também colaboradora do Programa de Pós-Graduação em Desenvolvimento Regional - PPGDR, da Universidade Estadual da Paraíba (UEPB). E-mail: rosilenemontenegro@gmail.com.

\section{Referências}

ALTHUSSER, Louis. Ler o Capital. Rio de Janeiro: Zahar, 1975.

ARAÚJO, Tânia Bacelar de. Ensaios Sobre o Desenvolvimento Brasileiro. Rio de Janeiro: Revan, 2000.

BENSAÏD, Daniel. Marx, o intempestivo: grandezas e misérias de uma aventura crítica. Rio de Janeiro: Civilização Brasileira, 1999.

BIANCHI, Alvaro. Trazendo o Estado de volta para a teoria: o debate Poulantzas-Miliband revisitado. $31^{\circ}$ Encontro Anual da ANPOCS, Caxambu (MG), 2007. Disponível em: <http://www.anpocs.com/index.php/papers-31-encontro/st-7/st22-4/2997-alvarobianchitrazendo/file>. Acesso em: 24 jul. 2017.

BOITO JUNIOR, Armando. Os atores e o Enredo da Crise Política. In: JINKINGS, Ivana; DORIA, Kim; CLETO, Murilo (Orgs.). Por Que Gritamos Golpe? Para entender o impeachment e a crise política no Brasil. 1. ed. São Paulo: Boitempo, 2016.

. Estado, Política e Classes Sociais: ensaios teóricos e históricos. São Paulo: UNESP, 2007.

BRASIL JUNIOR, Antonio; OLIVEIRA, Marcelo de. Breve Introdução à Jeffrey Alexander. Revista Estudos Políticos, v. 5, n. 2, p. 345-350, dez. 2014.

BRESSER-PEREIRA, Luiz Carlos. A Construção Política do Estado. Lua Nova, v. 81, p. 117-146, 2010.

CESÁRIO, Ana Cleide Chiarotti; ALMEIDA, Ana Maria Chiarotti. Discurso e Ideologia: reflexóes no campo do Marxismo estrutural. Acta Scientiarum. Human and Social Sciences, v. 32, n. 1 p. 1-8, 2010.

ENGELS, Friedrich. [Carta] 21 set. 1890, [para] BLOCH, Joseph. Resposta para pergunta: o que Marx e ele próprio entendiam por materialismo histórico e se a produção e reprodução da vida real 
constituíam, a seu ver, o único fator determinante. In: MARX, Karl; ENGELS, Friedrich: Estudos Filosóficos. [S.1.]: Editions Sociales, 1951.

FATTORELLI, Maria Lúcia. A dívida pública é um mega esquema de corrupção intitucionalizado. Carta Capital, 9 jun. 2015. Disponível em: <https://www.cartacapital.com.br/economia/201cadivida-publica-e-um-mega-esquema-de-corrupcao-institucionalizado201d-9552html>. Acesso em: 19 dez. 2017.

FERNANDES, Florestan. O Surgimento do Antivalor: capital, força de trabalho e fundo público. Novos Estudos, n 22, p. 8-28, out. 1988.

FORRESTER, Viviane. O Horror Econômico. São Paulo: Editora da Universidade Estadual Paulista, 1997.

FOUCAULT, Michel. A Ordem do Discurso: aula inaugural no Collège de France pronunciado em 2 de dezembro de 1970. São Paulo: Ediçóes Loyola, 2012.

. Microfísica do Poder. 24. ed. São Paulo: Edições Gerais, 2007.

GONÇALVES, Hugo Feitosa; MONTENEGRO, Rosilene Dias. Desenvolvimento do Nordeste nos Governos FHC e Lula. VIII Seminário Internacional sobre Desenvolvimento Regional: territórios, redes e Desenvolvimento Regional - perspectivas e desafios, Santa Cruz do Sul (RS), 2017. Disponível

em: $<$ http://online.unisc.br/acadnet/anais/index.php/sidr/article/download/16669/4431>. Acesso em: 21 maio 2019.

GUSMÃO, Luís de. O Fetichismo do Conceito: limites do conhecimento teórico na investigação social. Rio de Janeiro: Topbooks, 2012.

HAMLIN, Cynthia Lins. Realismo Crítico. In: SELL, Carlos Eeduardo; MARTINS, Carlos Benedito (Orgs.). Teoria Sociológica Contemporânea: autores e perspectivas. São Paulo: Annablume, 2017. p. 47-74.

HARVEY, David. O Enigma do Capital: e as crises do capitalismo. São Paulo: Boitempo, 2011. O Novo Imperialismo. 4. ed. Sáo Paulo: Ediçóes Loyola, 2010.

HOWLETT, Michael; RAMESH, M.; PERL, Anthony. Política Pública: seus ciclos e subsistemas uma abordagem integral. Rio de Janeiro: Elsevier, 2013.

HUNT, Emery Kay. História do Pensamento Econômico. 7. ed. Rio de Janeiro: Campus, 1989.

LENIN, Vladmir Ilich. O Imperialismo: fase superior do capitalismo. 4. ed. São Paulo: Global, 1987.

LÖWY, Michael. Ideologias e Ciências Sociais: elementos para uma análise marxista. São Paulo: Cortez, 1989.

MARX, Karl. O 18 Brumário de Luís Bonaparte. 2. ed. São Paulo: Martin Claret, 2008.

. Contribuiçóes à Crítica da Economia Política. 1. ed. São Paulo: Martin Fontes, 1977.

MARX, Karl; ENGELS, Friedrich. Manifesto do Partido Comunista. 1. ed. São Paulo: Penguin Classics/Companhia das Letras, 2012.

A Ideologia Alemã: Feuerbach - a contraposição entre as cosmovisóes materialistas e idealistas. São Paulo: Martin Claret Ltda, 2010.

MASZAROS, István. Estrutura Social e Formas de Consciência: a determinação social do método. São Paulo: Boitempo, 2009.

O'CONNOR, James. USA: a crise do Estado capitalista. Rio de Janeiro: Paz e Terra, 1977.

PEREIRA, José Maria Dias. Uma Breve História Sobre o Desenvolvimentismo no Brasil. Cadernos do Desenvolvimento, v. 6, n. 9, p. 121-141, 2011. 
POULANTZAS, Nicos. O Estado Capitalista: uma resposta a Milibande e Laclau. Crítica Marxista, n. 27, p. 105-127, 2008.

. O Estado, O Poder, O Socialismo. Rio de Janeiro: Ediçóes Graal, 1980.

. Poder Político e Classes Sociais. São Paulo: Martins Fontes, 1977.

ROJAS, Gonzalo Adrián. Caracterizando os governos "pós-neoliberais" latino-americanos. Libertas, v. 15, n. 1 n 2015.2 Disponível em: <http://ojs2.ufj.emnuvens.com.br/libertas/article/view/18311/9534>. Acesso em: 12 mar. 2017.

ROJAS, Gonzalo Adrián; AMADEO, Javier. As classes sociais em Nicos Poulantzas e Erik Olin Wright e sua importância na análise dos processos políticos contemporâneos. In: $39^{\circ}$ Encontro Anual da ANPOCS, Caxambu (MG), 2017. Disponível em: $<$ http://www.anpocs.com/index.php/papers-39-encontro/gt/gt20/9627-as-classes-sociais

-em-nicos-poulantzas-e-erik-olin-wright-e-sua-importancia-na-analise-dos-processos

-politicos-contemporaneos/file>. Acesso em: 10 maio 2017.

SECCHI, Leonardo. Políticas Públicas: conceitos, esquemas de análise, casos práticos. 2. ed. São Paulo: Cengage Leaning, 2016.

SISCÚ, João; PAUA, Luiz Fernando de; MICHEL, Renault. Por Que Novo-desenvolvimentismo? Revista de Economia Política, v. 27, n. 4, p. 507-524, 2007. Disponível em: <http://www.scielo.br/scielo.php?script=sci_arttext\&pid=S0101-31572007000400001 >. Acesso em: 07 ago. 2017.

THOMPSON, John Brookshire. Ideologia e Cultura Moderna: teoria social crítica na era dos meios de comunicação de massa. Petrópolis, RJ: Vozes, 1995.

Texto recebido em 07 de dezembro de 2018. Aprovado em 17 de julho de 2019. 